\title{
TU/e emonownen

\section{Characterization of elastomer sliding behavior across silica and polydimethylsiloxane grafted surfaces}

\section{Citation for published version (APA):}

Genieser, L. H., Hendriks, C. P., Baaijens, F. P. T., \& Meijer, H. E. H. (2000). Characterization of elastomer sliding behavior across silica and polydimethylsiloxane grafted surfaces. Journal of Rheology, 44(5), 1003-1017. https://doi.org/10.1122/1.1289285

DOI:

$10.1122 / 1.1289285$

Document status and date:

Published: 01/01/2000

\section{Document Version:}

Publisher's PDF, also known as Version of Record (includes final page, issue and volume numbers)

\section{Please check the document version of this publication:}

- A submitted manuscript is the version of the article upon submission and before peer-review. There can be important differences between the submitted version and the official published version of record. People interested in the research are advised to contact the author for the final version of the publication, or visit the $\mathrm{DOI}$ to the publisher's website.

- The final author version and the galley proof are versions of the publication after peer review.

- The final published version features the final layout of the paper including the volume, issue and page numbers.

Link to publication

\section{General rights}

Copyright and moral rights for the publications made accessible in the public portal are retained by the authors and/or other copyright owners and it is a condition of accessing publications that users recognise and abide by the legal requirements associated with these rights.

- Users may download and print one copy of any publication from the public portal for the purpose of private study or research.

- You may not further distribute the material or use it for any profit-making activity or commercial gain

- You may freely distribute the URL identifying the publication in the public portal.

If the publication is distributed under the terms of Article 25fa of the Dutch Copyright Act, indicated by the "Taverne" license above, please follow below link for the End User Agreement:

www.tue.nl/taverne

Take down policy

If you believe that this document breaches copyright please contact us at:

openaccess@tue.nl

providing details and we will investigate your claim. 


\title{
Characterization of elastomer sliding behavior across silica and polydimethylsiloxane grafted surfaces
}

\author{
Lars H. Genieser, ${ }^{\text {a) }}$ Kees C. P. Hendriks, ${ }^{\text {b) }}$ Frank T. P. Baaijens, \\ and Han E. H. Meijer \\ Materials Technology, Dutch Polymer Institute, Eindhoven University \\ of Technology, P.O. Box 513, 5600 MB Eindhoven, The Netherlands
}

(Received 29 March 1999; final revision received 27 June 2000)

\begin{abstract}
Synopsis
A novel combination of experimental techniques including a lateral force apparatus was developed for the purpose of characterizing the slip of polymer materials over hard surfaces. Quantitative shear stress data were obtained by sliding a crosslinked polydimethylsiloxane elastomer across smooth flat-tipped styli (mesas). A first set of mesas had a native silica ( $\mathrm{SiO})$ surface; a second set was functionalized with linear hydroxyl-terminated polydimethylsiloxane (PDMS-OH) polymers. The shear stress associated with sliding across the $\mathrm{SiO}$ mesas was as much as a factor of 10 greater than that for sliding across the PDMS-OH functionalized mesas. Possible mechanisms underlying this difference in behavior are discussed. (C) 2000 The Society of Rheology. [S0148-6055(00)01405-X]
\end{abstract}

\section{INTRODUCTION}

The slip of polymer melts has been thought to play an important role in the onset of surface melt fracture (OSMF) in the extrusion of these materials. Such transitions limit product throughput and, hence, the economic potential of a process. A distinct, yet related technological problem concerns the friction of elastomers over hard surfaces: in devices such as drive belts slippage should be avoided.

Ramamurthy (1986) noted OSMF for linear low-density polyethylene (LLDPE) above a critical wall shear stress; the slope of the wall shear rate versus stress curve abruptly changed above this critical shear stress. Ramamurthy concluded that the OSMF was induced by the onset of slip in the die land. Certain brass alloys, from which the die land was constructed, were effective in delaying the onset of melt fracture; Ramamurthy concluded that these materials had the best adhesion with the polymer, reducing slip. Halley and Mackay (1994) concluded from their experimental results that improved adhesion between a brass die wall and LLDPE polymer melt reduced slip and increased extrusion pressure for a given flow rate. Ghanta et al. (1999) found that use of a brass alloy for the die land resulted in delay of the onset of melt fracture. Their experiments shed light on the effect of a nitrogen blanket over the extruder feed and an abrasive

\footnotetext{
${ }^{a)}$ Present address: Union Carbide Corporation, P.O. Box 670, Bound Brook, NJ 08805. Author to whom all correspondence should be addressed. Electronic mail: genieslh@ucarb.com

${ }^{b}$ Present address: Royal Philips Electronics, Center for Industrial Technology, P.O. Box 218, 5600 MD Eindhoven, The Netherlands.
} 
additive on the ability of brass alloys to delay or eliminate the onset of melt fracture. Ghanta et al. concluded that melt fracture suppression was a result of enhanced slip over the brass die land, in contrast to the conclusion of Ramamurthy (1986).

The slip of polymer melts over surfaces has been proposed to occur via one of two mechanisms, adhesive or cohesive failure [Baljon and Robbins (1997)]. In the adhesive failure mechanism, at low shear stresses, the polymer molecules adhere to the wall. Above a critical shear stress, debonding occurs and the molecules slide along the wall. In the cohesive failure mechanism, a layer of polymer always remains adhered to the wall. Above a critical shear stress, molecules in this first layer become stretched and disentangle from the rest of the polymer melt in the bulk flow, resulting in slip [BrochardWyart et al. (1996)]. This process could also be dependent on the wall material, since the surface density and conformation of polymers adhered to the wall could depend on the density of sites available for bonding. Baljon and Robbins (1997) conducted moleculardynamics simulations of shearing of polymer between two walls and found that slip could occur either within the polymer (cohesive failure via polymer chain disentanglement) or at the wall (adhesive failure via polymer-wall debonding), depending on the strength of the polymer wall bonds.

In recent years, several careful studies have considered disentanglement of polymer molecules in the bulk melt from polymer molecules adhered to a wall. Léger et al. (1997) used a polydimethylsiloxane (PDMS) melt flowing over a silica surface grafted with a pseudobrush of PDMS molecules and measured slip within a region extending $100 \mathrm{~nm}$ from the silica surface via an optical technique. Léger et al. identified two distinct slip regimes: a low slip regime in which the slip velocity increased linearly with the shear rate and a high slip regime in which the slip velocity increased with a high power of the shear rate. A critical shear rate demarcated these two regimes. The observations of Léger et al. were in accordance with the theoretical predictions of Brochart-Wyart et al. (1996). Georges et al. (1996) considered the case of sliding of two monolayers of polyisoprene adsorbed onto two opposed surfaces. They observed that within a certain regime of sliding velocities, the friction force decreased with increased sliding speed. Georges et al. attributed this to increased ordering of the polymer layers under shear stress; this picture is similar to that of Brochart-Wyart et al. (1996). Both the Léger et al. and Georges et al. studies focused only on systems in which slip occurred via polymer chain disentanglement.

Deruelle et al. (1995) conducted a study of the adhesion energy between a crosslinked PDMS elastomer and a bare silica surface or silica surfaces grafted with hydroxylterminated polydimethylsiloxane (PDMS-OH) molecules. They found that the work for surfaces separation (adhesion energy) between the PDMS elastomer and PDMS-OH surfaces grafted from PDMS-OH solutions within a certain concentration range was greater than the work for surfaces separation between the elastomer and the bare silica surface. Deruelle et al. mentioned in their paper that a possible interpretation of these results was that interpenetration between the grafted PDMS-OH molecules and the crosslinked elastomer chain network occurred. In contrast, the work for surfaces separation between the PDMS elastomer and PDMS-OH surfaces grafted from the melt was less than the work associated with solution grafted PDMS-OH surfaces and less than the work associated with separation of the elastomer from a bare silica surface. In the study, the work for surfaces separation was determined by means of measuring the area of contact and the force in the direction normal to the plane of the two surfaces at the point of contact upon translation of the two surfaces relative to each other in the normal direction. The Deruelle et al. study did not address the shear stress required to effect sliding of the elastomer across the opposed surface. 


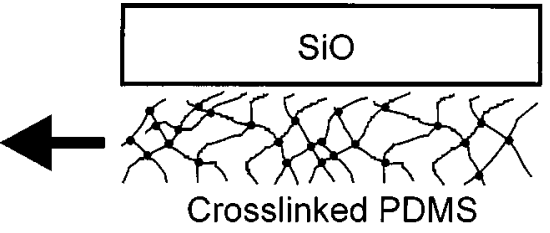

(a)

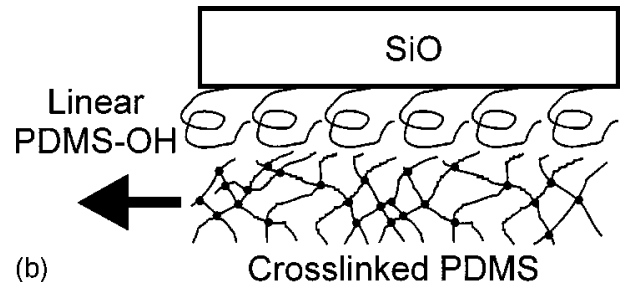

(b)

FIG. 1. (a) Sliding of a crosslinked PDMS elastomer across a silica $(\mathrm{SiO})$ surface. (b) Sliding of a crosslinked PDMS elastomer across a layer of linear PDMS-OH molecules bonded to a silica surface.

A system in which a crosslinked elastomer slides over a hard surface resembles the system of a polymer melt slipping across a surface: in both systems a polymer network slides across a surface. In the case of a polymer melt, in which the network is formed by entanglements, individual chains can attach to the surface and disentangle from the bulk. By contrast, in a crosslinked elastomer, the covalently linked polymer chains cannot separate from the network. Hence, unless the shear stress is sufficiently high to break covalent bonds, sliding occurs between the elastomer and the hard surface. In sliding over rough surfaces, energy is converted to heat via hysterisis in the repeated loading/ unloading of the elastomer; this gives rise to deformational friction [Suh (1986)]. For a low imposed normal stress and sufficiently smooth hard surface, the deformational contribution to friction is negligible. In this case, friction arises from the breaking of linkages of an indeterminate nature between the elastomer and the hard surface [Suh (1986)].

In the past, Grosch (1962) and Ludema and Tabor (1966) considered sliding of an elastomer over a hard surface, such as glass or steel. However, the hard surface was only smooth from a macroscopic viewpoint; it was not characterized on a microscopic scale. In the experiment of Ludema and Tabor the contact area was inferred indirectly which made it difficult to report results in terms of friction stress rather than friction coefficient. To the authors' knowledge, more precise experiments to probe the nature of friction associated with bonding between an elastomer and a hard surface have not been recently conducted.

The objective of the present experiment was to obtain quantitative data to elucidate differences between the frictional behavior exhibited by a crosslinked PDMS elastomer sliding over a smooth, hard silica surface [cf. Fig. 1(a)] and the elastomer sliding over a PDMS-OH grafted surface [cf. Fig. 1(b)]. The roughness of the hard surfaces was well characterized; the area of the surfaces was known so that results could be reported in terms of shear and normal stress, rather than only friction coefficient. The data presented herein may provide additional tests for the verification of theories which model slip and friction in polymeric systems.

\section{EXPERIMENT}

A diagram of the lateral force apparatus (LFA), which controlled sliding velocity and measured forces in order to obtain information for the study, is shown in Fig. 2. A piece of elastomeric material, described later, was placed onto a stage, which moved at a controlled velocity, $V$. A probe tip, the end of which had a raised flat surface (mesa), was affixed to a cantilever unit. The cantilever unit was composed of normal and lateral double parallel leaf-spring sections (cf. close-up view of Fig. 3). When a normal (or lateral) force was applied, the normal (or lateral) double parallel leaf spring deformed into an " $S$ " shape such that the surface of the mesa remained parallel to the substrate. Specifically, normal and lateral deflections of the respective leaf springs induced minimal 


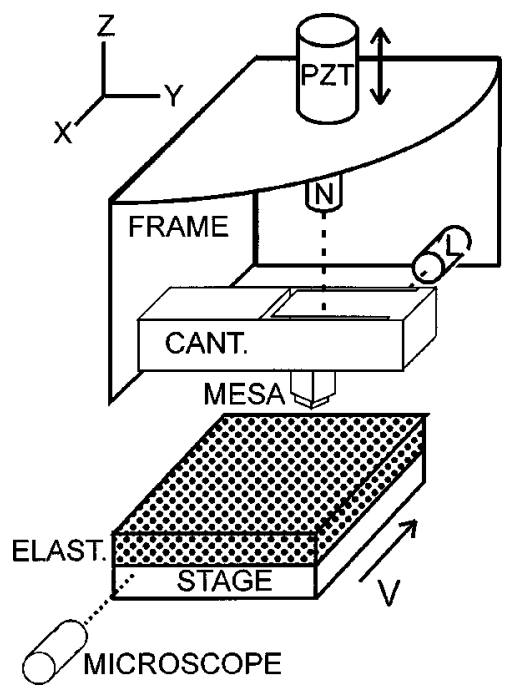

FIG. 2. Diagram of LFA used in the study. The location of the MESA on the probe tip attached to the cantilever unit (CANT.), which is attached to the FRAME, is shown. The location of the normal $(N)$ and lateral $(L)$ optical heads on the FRAME is indicated. The PZT translates the MESA normal to the elastomer surface. The elastomer (ELAST.) is coated on the silicon wafer (not shown). The elastomer and wafer are mounted on the translation STAGE which moves the elastomer surface parallel to the MESA surface. The optical axis of the MICROSCOPE is parallel to the direction of sliding.

angulation of the end of the leaf spring. The vertical position of the mesa was set by a piezotransducer (PZT) (cf. Fig. 2). A feedback loop between the PZT and an optical head capable of determining the displacement of the normal double parallel leaf spring via a laser-defocusing technique ensured that the normal force remained constant during sliding. Such a feedback loop was necessary since otherwise the occasional encounter of a dust particle or other surface asperity could affect the normal force over the course of sliding. The procedure for aligning the surfaces is described later and the microscope objective used in the procedure is shown in Fig. 2; the optical axis of the microscope was parallel to the direction of sliding. A second optical head measured the displacement of the lateral double parallel leaf spring. Through a calibration procedure, the spring constant relating normal displacement to normal force was determined. The normal forces were then calculated from the measured normal leaf spring displacements in conjunction

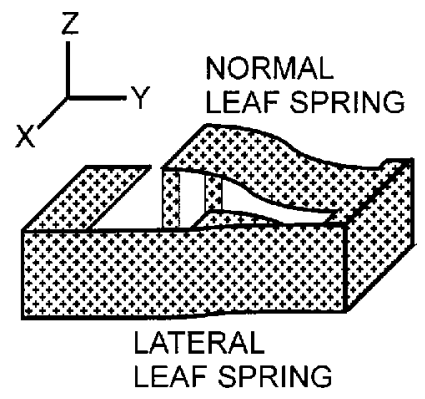

FIG. 3. A close-up view of the cantilever unit which is composed of NORMAL and LATERAL double parallel leaf springs. The section of the lateral leaf spring in the background is not shown so as not to clutter the diagram. 


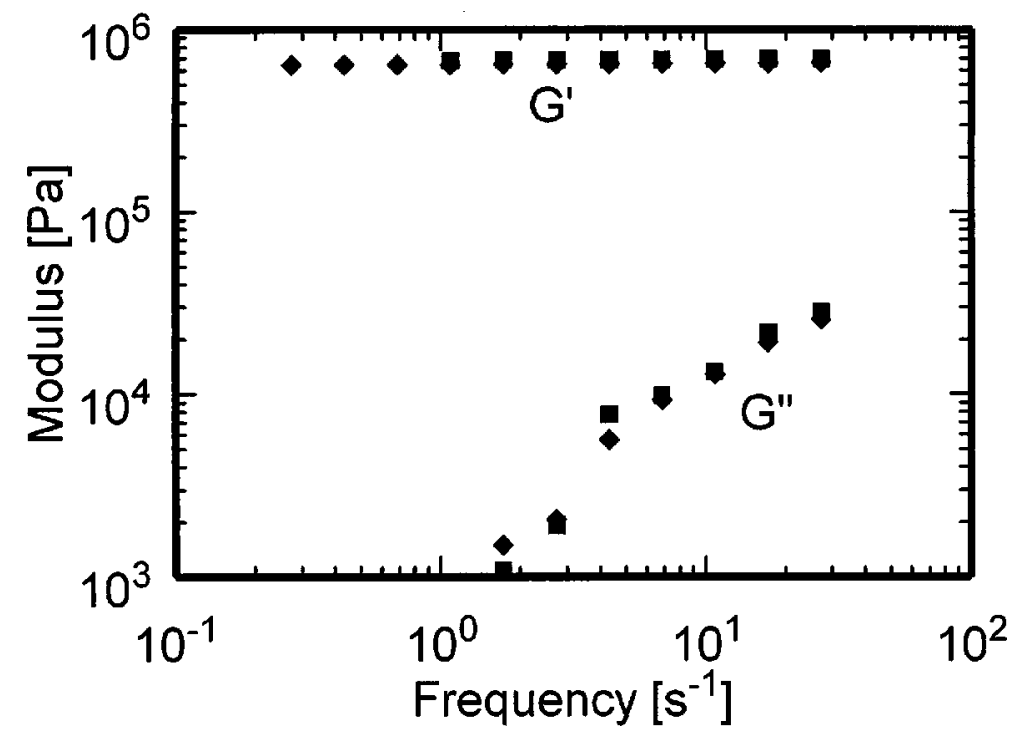

FIG. 4. Storage $\left(G^{\prime}\right)$ and loss $\left(G^{\prime \prime}\right)$ moduli for the Sylgard 184 elastomer during cure. Moduli of the Sylgard 184 cured and measured at a temperature of $100 \pm 2{ }^{\circ} \mathrm{C}$ after a cure time of about $28 \min (\diamond)$ and $44 \min (\boldsymbol{\square})$ are shown.

with the normal spring constant. In a similar manner, the lateral forces were calculated from the lateral leaf spring displacements and the determined lateral spring constant. The LFA with the cantilever used in the present experiment could resolve normal forces of 3 $\mu \mathrm{N}$ and measure normal forces as great as $3 \times 10^{3} \mu \mathrm{N}$; lateral forces of $0.6 \mu \mathrm{N}$ could be resolved and lateral forces up to $1.7 \times 10^{3} \mu \mathrm{N}$ could be measured. See Hendriks (2000) for more detail regarding the LFA.

The elastomer surface was formed by a procedure in which care was taken to ensure production of a flat, dust-free surface. A silicone elastomer with the trade name Sylgard 184, manufactured by Dow Corning, was used. More detailed information on the chemical composition of the elastomer was considered a trade secret and could not be obtained; it was assumed that Sylgard 184 consisted primarily of PDMS. The two components of the Sylgard 184 kit were combined to produce a mixture with a viscosity of approximately $4 \mathrm{~Pa}$ s. This mixture was then spin coated onto a silicon wafer spinning at a rate of approximately $5000 \mathrm{rpm}$. The thickness of the layer was controlled by adjusting the spin time, a spin time of $11 \mathrm{~s}$ was used to obtain a layer $24 \pm 5 \mu \mathrm{m}$ thick. The coated layer was then cured under nitrogen in an oven for $1 \mathrm{~h}$ at $100^{\circ} \mathrm{C}$. The silicon wafer with the elastomer layer was then immersed for $18 \mathrm{~h}$ in hexane filtered with a $0.2 \mu \mathrm{m}$ Teflon filter (Millipore Millex-FG); this step extracted free, unbound PDMS chains from the elastomer matrix.

The linear viscoelastic material functions of the Sylgard elastomer were measured in a RMS-800 rheometer (Rheometrics) as follows. The two-component uncured mixture was placed between two aluminum plates of radius $12.5 \mathrm{~mm}$; the plates were lowered to a gap of approximately $1 \mathrm{~mm}$. The mixture was then cured for about $44 \mathrm{~min}$ at a temperature of $100 \pm 2{ }^{\circ} \mathrm{C}$. Dynamic frequency sweeps were performed during the cure cycle. Storage $\left(G^{\prime}\right)$ and loss $\left(G^{\prime \prime}\right)$ moduli are shown in Fig. 4 for cure times in the rheometer of 28 and $44 \mathrm{~min}$ at a temperature of $100 \pm 2{ }^{\circ} \mathrm{C}$; the agreement between the two sets of data confirmed that the material was fully cured at $44 \mathrm{~min}$. This demonstrated that the condi- 
TABLE I. Dimensions and areas of the mesas used in the study.

\begin{tabular}{ccc}
\hline \hline Surface coating & $\begin{array}{c}\text { Dimensions } \\
(\mu \mathrm{m})\end{array}$ & $\begin{array}{c}\text { Area } \\
\left(\mu \mathrm{m}^{2}\right)\end{array}$ \\
\hline $\mathrm{SiO}$ & $55 \times 47 \pm 1$ & $2.6 \times 10^{3}$ \\
$\mathrm{SiO}$ & $95 \times 95 \pm 1$ & $9.1 \times 10^{3}$ \\
PDMS-OH & $56 \times 55 \pm 1$ & $3.1 \times 10^{3}$ \\
PDMS-OH & $95 \times 95 \pm 1$ & $9.0 \times 10^{3}$ \\
\hline \hline
\end{tabular}

tions used for curing the elastomer layer on the silicon wafer, as described in the preceding paragraph, resulted in full curing of the elastomer.

The probe tips were manufactured via a microlithography process at the DIMES center at the Delft University of Technology (Delft, The Netherlands). A square feature was protected by photoresist and the remaining exposed wafer area dry etched to a depth of $31 \pm 4 \mu \mathrm{m}$ to form raised "mesas." Mesas of different sizes were produced. Probe tips with square mesas of cross-sectional area $3 \times 10^{3}$ and $9 \times 10^{3} \mu \mathrm{m}^{2}$ were used in the present experiments; the dimensions are given in Table I.

The etched wafer was sawed to produce probe tips having dimensions of approximately $0.5 \times 0.5 \times 0.5 \mathrm{~mm}$ which could then be affixed to the cantilever. A silica ( $\mathrm{SiO})$ layer of $1.2 \pm 0.2 \mu \mathrm{m}$ thickness was left on the mesa after fabrication in order to protect it. Prior to use in the experiment, this rough oxide layer was stripped off to reveal the underlying smooth silicon surface via immersion in an ammonia-buffered hydrofluoric acid solution for approximately $8 \mathrm{~min}$ followed by rinsing in distilled water for at least 10 min. A new, thin oxide layer formed spontaneously upon exposure to air; the mesa surface remained flat and smooth. An estimate of the roughness was obtained by imaging the surface of the mesa with an atomic force microscope (Nanoscope IIIa). Over the imaged area of $2.5 \times 2.5 \mu \mathrm{m}$, the maximum variation in height of the surface was only 2 $\mathrm{nm}$ : the mesa had a smooth surface. Immediately prior to use, the mesas were examined with an optical microscope. A few small (approximately $1 \mu \mathrm{m}^{2}$ ) chips were noted on the mesas. There was concern initially that such chips could increase the contribution of deformation to the shear stress; the shear stress was determined from the measured lateral force and known mesa area. However, the contribution of deformation was found to be negligible, as described in Sec. III.

One set of probe tips was manufactured following the procedure described in the preceding paragraph such that the surfaces of the mesa were silica. The surfaces of a second set of mesas were functionalized with a pseudobrush [Léger et al. (1997)] of PDMS molecules by means of a procedure described in Deruelle et al. (1995). The silica surface of a mesa was coated with a drop of PDMS-OH. The PDMS-OH was purchased from Aldrich Chemical Co. and had a nominal kinematic viscosity of $20000 \mathrm{cSt}$ and a density of $0.97 \mathrm{~g} \mathrm{~cm}^{-3}$, hence, a viscosity of $19 \mathrm{~Pa}$. This viscosity corresponded to an average molecular weight of $72 \mathrm{~kg} \mathrm{~mol}^{-1}$ and a mean radius of gyration of $16 \mathrm{~nm}$ [Rhone-Poulenc (1994); Kurata and Tsunashima (1989)]. The probe tip was then heated under nitrogen in an oven for $7 \mathrm{~h}$ at $120^{\circ} \mathrm{C}$ in order to react the hydroxyl end groups of the PDMS-OH with the silanol groups on the silica surface of the mesa to produce a molecule grafted to the surface with the structure (PDMS)-O-Si. Note that the PDMS molecule was affixed to the silicon wafer not only through covalent bonding at the locations of the terminal hydroxyl groups, but also by hydrogen bonds between oxygen atoms in the PDMS chain backbone and surface silanol groups [Cohen-Addad (1989)]. Following the heating step, excess PDMS-OH material was removed by placing the 
probe tips in hexane for $15 \mathrm{~h}$, then replacing the solution with fresh hexane, and again allowing the tips to remain in the hexane for about $24 \mathrm{~h}$. The resultant mesa had a pseudobrush of PDMS-OH molecules adsorbed onto the surface.

The effectiveness of the PDMS-OH functionalization procedure was then checked. A drop of PDMS-OH was placed onto a wafer with a silica surface and heat treated and rinsed as described earlier. When the functionalized surface was exposed to water vapor, a dark stain on the region of the surface where the drop had been was rendered visible. The thickness of the layer was measured. The stain was lightly scratched with a sharp instrument to remove the PDMS-OH material but not damage the silicon surface. A region of $100 \times 100 \mu \mathrm{m}$ surrounding the scratch was then imaged via the amplitude signal of an atomic force microscope (AFM) in tapping mode. The region around the scratch had no apparent holes or bare spots, indicating an even coat of the PDMS-OH material over the silica surface. The area of the scratch could be distinguished from the surrounding region in the AFM image. The height signal was used to estimate the depth of the scratch; this was difficult since the border of the scratch was not well defined. However, the depth of the PDMS-OH layer did not appear to exceed $10 \mathrm{~nm}$. This was consistent with a monolayer of PDMS-OH having been grafted onto the silica surface. Specifically, for a PDMS-OH brush adsorbed from the melt onto a silica surface, the thickness is experimentally observed to be equal to $h=a N^{1 / 2}$, where $N$ is the index of polymerization and $a \sim 0.5 \mathrm{~nm}$ [Léger et al. (1997)]. For the PDMS-OH brush in the present experiment, $h=16 \mathrm{~nm}$ was obtained from this equation, consistent with the AFM observations. A qualitative experiment was performed to assess the strength of bonding of the PDMS-OH molecules to the silica surface. A piece of cured Sylgard 184 elastomer was manually pressed against the PDMS-OH stain and rubbed across the stain. The stain remained where the Sylgard had been rubbed. This indicated that the bonding of the PDMS-OH molecules to the silica was stronger than forces associated with any entanglement of the PDMS-OH molecules with the crosslinked Sylgard elastomer. Therefore, when the elastomer surface was slid across the mesa, the PDMS-OH brush remained fixed to the $\mathrm{SiO}$ surface of the mesa.

The facts that AFM imaging revealed no holes or bare spots in the coatings and the PDMS-OH coating remained adhered to the silica surface upon rubbing with a piece of Sylgard elastomer would indicate that, in the course of sliding of the Sylgard elastomer across the PDMS-OH grafted mesa, friction arose from the interaction of the Sylgard elastomer with the PDMS-OH layer. However, as mentioned earlier, in addition to the covalent bonding of the chain ends, portions of the chain backbone of the grafted PDMS-OH molecules are hydrogen bonded to silanol groups on the mesa surface. Such hydrogen bonds are expected to be in a state of dynamic equilibrium [Cohen-Addad et al. (1985)]. Thus, it cannot be ruled out that some silanol binding sites on the silica surface may become vacant during sliding, so that the Sylgard elastomer molecules may penetrate the PDMS-OH layer and interact directly with the silica surface. Nevertheless, the results presented in the next section showed a dramatic difference between shear forces associated with sliding of Sylgard elastomer over a bare silica mesa and sliding of the elastomer over a PDMS-OH grafted mesa; this indicated that any interaction of the elastomer with the silica surface was of secondary importance for the case of sliding over the PDMS-OH mesa.

Alignment of the mesa with the substrate was achieved as follows. Given that the optical axis of the microscope was nearly parallel with the direction of sliding, it was necessary to install the mesa in a "diamond" configuration; i.e., one of the corners of the mesa pointed in the direction of sliding (cf. Fig. 2). Each corner of the mesa and the mirror image of that corner reflected by the elastomer surface was observed through the 
microscope; it was ensured that this spacing was the same for each of the three visible corners. Given that a distance of $1 \mu \mathrm{m}$ could be resolved with the microscope, alignment of the mesa with the elastomer surface could be achieved such that the inclination was no greater than $1 \mu \mathrm{m}$ of gap spacing in $50 \mu \mathrm{m}$ along a mesa edge. One important advantage of using an elastomer surface was the fact that it conforms to the mesa surface as the two surfaces are slid across each other. Therefore, any small inclination was inconsequential when a normal force was applied to the mesa; it could be assumed that contact with the elastomer was achieved over the full mesa area. All the experiments were conducted in a temperature controlled room at a temperature of $23 \pm 1{ }^{\circ} \mathrm{C}$.

As described earlier, the double parallel leaf spring design of the cantilever precluded a substantial change in inclination of the mesa relative to the elastomer surface attributable to bending of the normal leaf spring in the $y z$-plane upon application of a normal force. However, it was necessary to determine the magnitude of any torsion about the $y$ axis in the cantilever unit as a whole imposed by lateral forces during sliding. This was checked by observing the position of the mesa relative to the elastomer surface during sliding. In none of the measurements presented and discussed in Sec III was any change in the position of the mesa relative to the elastomer surface observed. Given the ability to resolve a change in position of $1 \mu \mathrm{m}$ along an approximately $50 \mu \mathrm{m}$ edge of the smallest pair of mesas with the mesas installed in the diamond configuration mentioned earlier, and the fact that no change in inclination was noted upon movement of the surfaces relative to each other, it followed from direct observation that any change in torsion of the cantilever about the $y$ axis of the cantilever upon sliding was less than $30 \mathrm{mrad}$. Finite element modeling of the cantilever was used to determine that the spring constant for torsion about the $y$ axis of the cantilever unit was $12 \mathrm{rad} \mathrm{N}^{-1} \mathrm{~m}^{-1}$. The maximum lateral force (force in the direction of sliding) applied from the elastomer to a mesa was $1.7 \times 10^{3} \mu \mathrm{N}$. It followed that the rotation of the mesa about the $y$ axis of the cantilever unit was at most $0.01 \mathrm{mrad}$; this corresponded to change in gap spacing across the mesa surface of at most $1 \mathrm{~nm}$, which was negligible.

\section{RESULTS}

The results of the investigation presented in terms of shear stress versus normal stress are shown in Figs. 5 and 6; the stresses were determined by dividing the measured force by the area of the mesa. The results of the tests conducted with mesas of area $3 \times 10^{3} \mu \mathrm{m}^{2}$ are considered first (cf. Fig. 5). Note that at low normal stresses, the shear stresses obtained with sliding the elastomer surface at a velocity of $1 \mu \mathrm{m} \mathrm{s}^{-1}$ across the $\mathrm{SiO}$ coated mesa were as much as a factor of 10 greater than for sliding across the PDMS-OH coated mesa.

The forms of the results obtained with mesas of area $9 \times 10^{3} \mu \mathrm{m}^{2}$ (cf. Fig. 6) were similar to those obtained with the $3 \times 10^{3} \mu \mathrm{m}^{2}$ mesas. Within the accuracy of the measurement, as indicated by the error bars, when the elastomer surface was slid across PDMS-OH mesas of area $9 \times 10^{3} \mu \mathrm{m}^{2}$ at low imposed normal stresses, i.e., less than $0.05 \mathrm{MPa}$, at a given velocity, the resultant shear stress was essentially identical to that for sliding across a PDMS-OH mesa of smaller area, $3 \times 10^{3} \mu \mathrm{m}^{2}$. Under conditions of elevated normal stress, the shear stress for sliding at a given velocity was lower for the case of the $9 \times 10^{3} \mu \mathrm{m}^{2}$ than for the $3 \times 10^{3} \mu \mathrm{m}^{2}$ mesa. For example, at a normal stress of $0.2 \mathrm{MPa}$, the shear stress at a velocity of $1 \mu \mathrm{m} \mathrm{s}^{-1}$ for the $9 \times 10^{3} \mu \mathrm{m}^{2}$ mesa was about $30 \%$ lower than that for the $3 \times 10^{3} \mu \mathrm{m}^{2}$ mesa. For the $\mathrm{SiO}$ coated mesas, at a nonzero normal stress of $0.05 \mathrm{MPa}$, the shear stress observed with sliding with the $9 \times 10^{3} \mu \mathrm{m}^{2}$ mesa was about $40 \%$ lower than that with the $3 \times 10^{3} \mu \mathrm{m}^{2}$ mesa. 


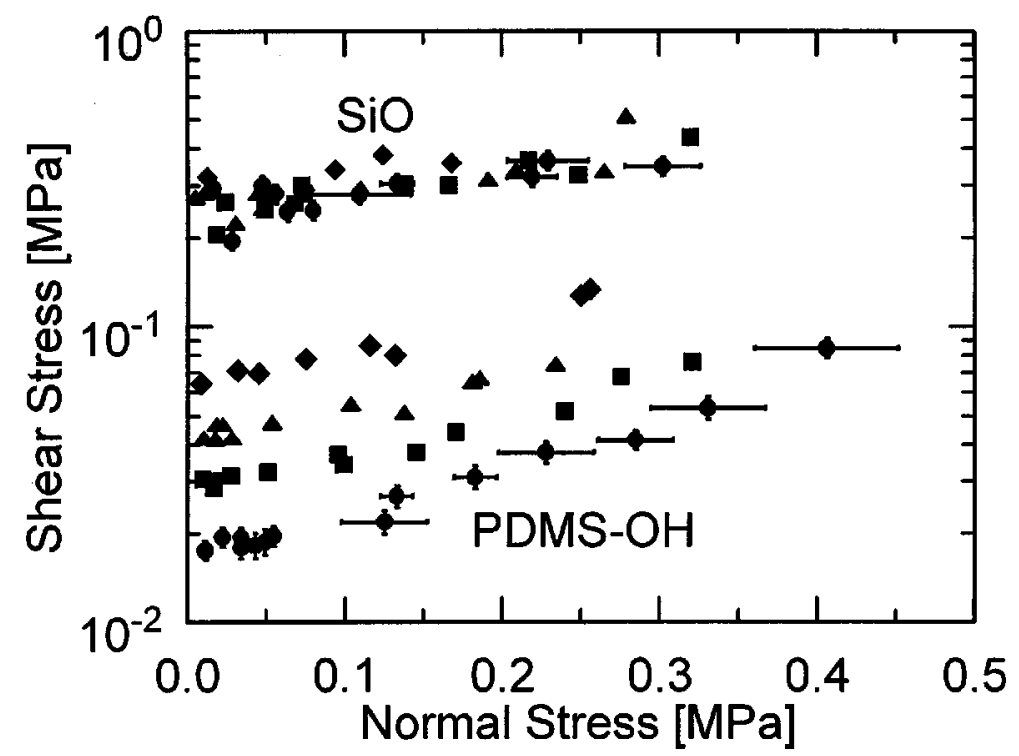

FIG. 5. The shear stress is shown as a function of the normal stress for the elastomer sliding over mesas of area $3 \times 10^{3} \mu \mathrm{m}^{2}$. Data for mesas with surfaces of $\mathrm{SiO}$ and PDMS-OH are shown. Data obtained for sliding velocities of $1(\bullet), 4(\boldsymbol{\square}), 11(\boldsymbol{\Delta})$, and $38(\diamond) \mu \mathrm{m} \mathrm{s}^{-1}$ are indicated by the symbols. Representative error bars are shown for data obtained at $1 \mu \mathrm{m} \mathrm{s}^{-1}$; error bars are only shown for data for which the normal stress was greater than $0.1 \mathrm{MPa}$ to avoid cluttering the graph.

For both the $3 \times 10^{3}$ and $9 \times 10^{3} \mu \mathrm{m}^{2}$ PDMS-OH coated mesas the shear stress increased with normal stress at a given velocity. Data obtained with the $\mathrm{SiO}$ coated mesas also appeared to exhibit an increase in shear stress with imposed normal stress. For the PDMS-OH mesas, a distinct increase in shear stress with sliding velocity at a given

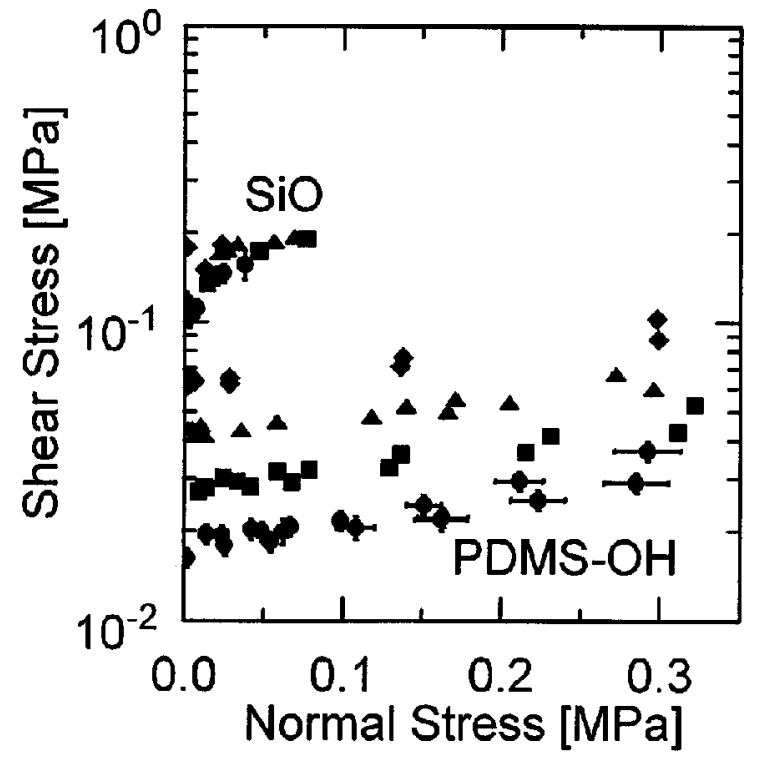

FIG. 6. Similar to Fig. 5, expect data were obtained with mesas of area $9 \times 10^{3} \mu \mathrm{m}^{2}$. 
imposed normal force was noted. Specifically, at an imposed normal stress close to zero, the stress for sliding over the PDMS-OH mesas at a rate of $38 \mu \mathrm{m} \mathrm{s}^{-1}$ was four times greater than for sliding at $1 \mu \mathrm{m} \mathrm{s}^{-1}$. Figures 5 and 6 illustrate that for the $\mathrm{SiO}$ coated mesas, the dependence of shear stress on velocity is weaker than for the PDMS-OH mesas; scatter in the data precluded specific identification of the relation between shear stress and velocity for the $\mathrm{SiO}$ mesas.

The observation that the shear stress induced by sliding the elastomer across the PDMS-OH mesa of $9 \times 10^{3} \mu \mathrm{m}^{2}$ area at an elevated imposed normal stress was lower than the shear stress exhibited by sliding of the elastomer across a mesa of area $3 \times 10^{3} \mu \mathrm{m}^{2}$ cannot be currently explained. The lower shear stress for the mesa of greater area could imply that there was a contribution to the stress which had weak or no dependence on the mesa area. The contribution to the shear stress associated with "peeling" the elastomer from the back edge of the mesa could be such a mechanism. The force associated with breaking linkages between the elastomer and the mesa surface is expected to vary linear proportionally with the area. In contrast, for the square mesas used in the present experiment, the length of the peeling edges and, therefore, the force associated with peeling varies only with the square root of the mesa area. Consequently, the dependence of the total shear force required to effect sliding on the area will be less than linear, so that the shear stress exhibits a sublinear inverse dependence on the area.

As the normal stress decreases toward zero, a finite nonzero value of the shear stress is approached (cf. Figs. 5 and 6). Even when the imposed normal stress falls to zero, the surfaces remain in contact. Sliding is opposed by the requirement to break linkages between the elastomer and the PDMS-OH or SiO coated mesa. (An interesting topic for future study would be to measure the shear stress during relative sliding of the surfaces when a negative normal force acting to separate the surfaces after initial contact is imposed.)

The shear stress developed when the two surfaces slide relative to one another is thought to be primarily related to Mode 2 fracture, i.e., the breaking of linkages between the mesa and the sliding elastomer under shear stress, and possibly peeling. Given that the relative motion of the elastomer with respect to the mesa is in the plane of the parallel surfaces, and a normal force is imposed to ensure contact between the mesa and the sliding substrate, Mode 1 fracture, i.e., the breakage of linkages and separation of the surfaces via their relative movement in opposite directions normal to the plane of the surfaces, is not expected to have made a substantial contribution to the shear stress in the present experiment.

The data are also displayed in terms of the friction coefficient in Figs. 7 and 8; the friction coefficient is defined as the ratio of the shear stress to the normal stress, $\mu=\tau / N$. A limiting value of the friction coefficient is approached at high normal stress, at least for the measurements with the PDMS-OH mesas. In contrast, as described earlier, as the normal force approaches zero, the shear stress approaches a limiting value; therefore, the friction coefficient grows rapidly and without bound as zero normal force is approached. The friction coefficient is not a useful parameter to describe sliding behavior under conditions of low or zero normal stress.

One concern with the present technique was the possible influence of deformational friction on the shear force measurements. Under an imposed normal force, the mesa deforms the region of the sliding elastomer surface across which it passes, first compressing and then releasing it. Because the rubber has a finite loss modulus, a part of the energy provided by sliding is converted to heat; this increases the shear stress associated with sliding [Suh (1986)]. The form of the sliding mesa (a "diamond" with a flat surface) complicates a detailed Hertzian analysis of the system. Nevertheless, the finding, 


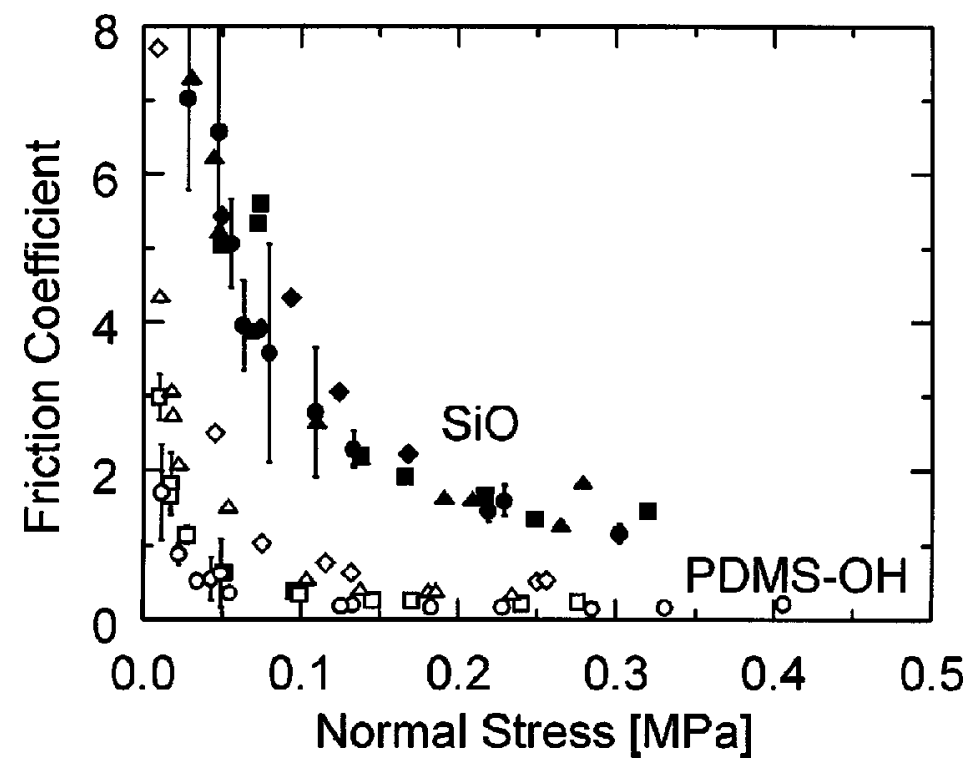

FIG. 7. Similar to Fig. 5, except friction coefficient is shown as a function of normal stress for sliding mesas of area $3 \times 10^{3} \mu \mathrm{m}^{2}$. Representative error bars are shown for data obtained at a sliding velocity of $1 \mu \mathrm{m} \mathrm{s}{ }^{-1}$; error bars are not shown when they are smaller than the associated symbol.

for the model case of a hard sphere sliding over an elastomer, that the contribution of deformation to the friction coefficient is zero for zero imposed normal stress and increases linearly from that point with increasing normal stress [Halling (1975)] is expected to apply to the case of the diamond-shaped mesas used in the present experiment as well.

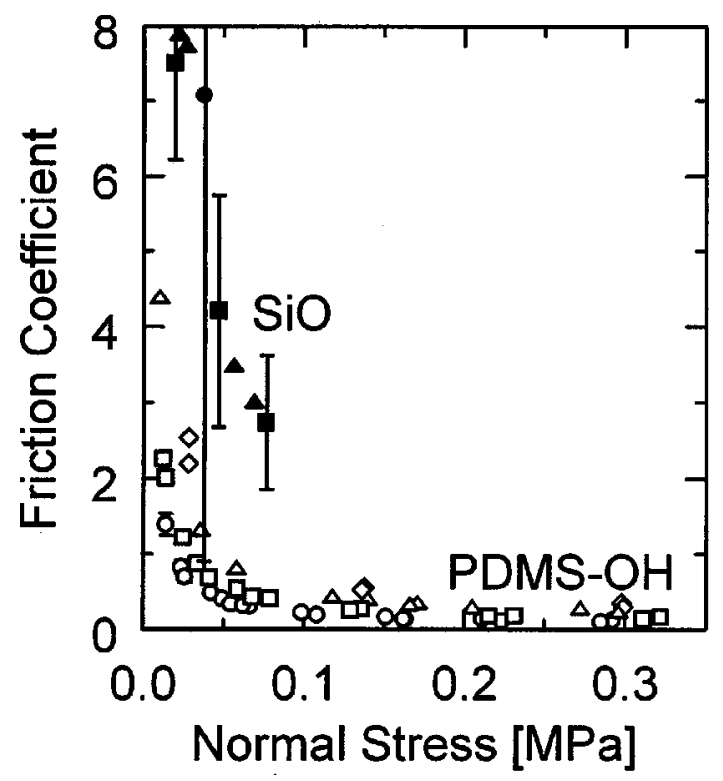

FIG. 8. Similar to Fig. 6 except friction coefficient is shown as a function of normal stress for sliding mesas of area $9 \times 10^{3} \mu \mathrm{m}^{2}$. Representative error bars are shown for data obtained with the PDMS-OH mesa at a sliding velocity of $1 \mu \mathrm{m} \mathrm{s}^{-1}$, and for data obtained with the $\mathrm{SiO}$ mesa at sliding velocities of 1 and $4 \mu \mathrm{m} \mathrm{s}^{-1}$. Error bars are not shown when they are smaller than the associated symbol. 
Therefore, if the contribution of deformation to the friction coefficient were significant, it should be noticeable in Figs. 7 and 8. For the case of the $3 \times 10^{3} \mu \mathrm{m}^{2}$ PDMS-OH mesa, a slight increase in the friction coefficient with normal stress was only noted for normal stresses greater than $0.25 \mathrm{MPa}$, specifically for data obtained at sliding velocities of 1 and $4 \mu \mathrm{m} \mathrm{s}^{-1}$. Even if this slight increase were the result of deformation of the elastomer, the contribution of deformation to the shear stress was certainly negligible for normal stresses less than 0.1 MPa. Since deformational friction was associated with the change in conformation of the elastomer surface, and was unrelated to the chemical functionality of the opposing hard surface, the contribution of deformation of the elastomer to the shear stress was no greater for the case of sliding across the $\mathrm{SiO}$ than for sliding across the PDMS-OH coated mesa. Consequently, the effects of deformation may be neglected for data obtained with the $\mathrm{SiO}$ mesa of area $3 \times 10^{3} \mu \mathrm{m}^{2}$. For the $9 \times 10^{3} \mu \mathrm{m}^{2}$ mesas no increase in the friction coefficient with normal stress was observed. One limitation of the present experiment arises from the fact that when the diamond-shaped mesa is pressed into the elastomer, the local normal stress varies with position on the mesa surface. In the present study, the results were reported in terms of an average stress determined by dividing the measured shear force by the mesa area.

Each data point provided in Figs. 5-8 represents a time-series average of 11-21 data points in an experimental run. The data points in a time series were separated by intervals of $1 \mathrm{~s}$ for lower velocity runs and $0.2 \mathrm{~s}$ for higher velocity runs. The standard deviation of the shear and normal force time series, along with the systematic errors associated with the LFA, was included in the calculation of the error bars shown in Figs. 5-8. In order to avoid cluttering the graph, a representative set of error bars is shown only for data obtained at one or two sliding velocities.

As described in Sec. II, a constant normal force was maintained on the probe tip by means of a feedback loop. For a given mesa, under certain conditions of normal stress and sliding velocity, the feedback loop could go into oscillation; this was noted from a "whining" sound emitted by the PZT. Since this phenomenon is generally not noted when the LFA is used in studying the sliding of metal across metal surfaces, it is probable that the PZT oscillation was related to the elastic nature of the Sylgard surface. This interpretation is supported by the observation that in some cases, when the normal force was increased from zero while there was no motion of the surfaces relative to each other, whining of the PZT was noted. Because there was no relative motion of the two surfaces, stick-slip phenomena could not have been responsible for inducing oscillation in the feedback mechanism in these cases. Rather, it appears that under certain conditions, for the system of the feedback loop coupled with the elastic surface, the "solution" to the associated dynamical equations of the mesa remaining at rest becomes unstable. Consequently, the slightest, inevitable perturbation induces the system to evolve toward a dynamic solution as manifested in the oscillation of the PZT.

The fact that sliding broadened the range of conditions under which the PZT oscillated may have been a consequence of low amplitude stick-slip motion. However, no characteristic "sawtooth" form of the lateral force often associated with stick-slip motion or any other regular pattern was noted from the time-series data. Stick-slip motion may have occurred for which the associated variation in the lateral force was below the level resolvable by the LFA, or the associated frequency was greater than could be resolved in the time-series output. In any event, the determined shear stress presented in the figures represents a value averaged over an interval of sliding time.

The onset of PZT oscillation could not be predicted but could sometimes be avoided by "tuning" the imposed normal force to a value where the oscillation ceased; presumably, this change of parameters of the dynamical system rendered the solution of the PZT 
remaining at a given position in the $z$-direction stable. In the case of sliding of the elastomer across the PDMS-OH mesas, the oscillation, when it occurred, was generally of sufficiently low amplitude such that data could be acquired. However, for sliding with the $\mathrm{SiO}$ mesas, onset of oscillation was more difficult to avoid and when oscillation occurred, it could be of great enough amplitude to preclude the acquisition of data; this is reflected in the limited number of data points acquired with the $\mathrm{SiO}$ mesas, particularly with the $9 \times 10^{3} \mu \mathrm{m}^{2} \mathrm{SiO}$ mesa. For all the data points shown in Figs. 5-8, when PZT oscillation occurred, the shear and normal forces oscillated within a limited range. Because the shear and normal forces oscillated within bands, we are confident that the data points in Figs. 5-8 are accurate within the range indicated by the error bars.

The vertical error bars for the friction coefficient (cf. Figs. 7 and 8) are large because they include contributions from both the shear and normal force measurements; it is not necessary to show horizontal error bars since these are provided for a given data point in Figs. 5 and 6. For certain data obtained at low normal stresses, variation in the normal stress was sufficiently large, specifically, some of the normal stress data in a given time series were negative, to preclude calculation of a meaningful friction coefficient; these data are not shown in Figs. 7 and 8. Since only one data point was available for a sliding velocity of $1 \mu \mathrm{m} \mathrm{s}^{-1}$ with the $9 \times 10^{3} \mu \mathrm{m}^{2} \mathrm{SiO}$ surface as presented in Fig. 8, error bars are also provided for data obtained with a sliding velocity of $4 \mu \mathrm{m} \mathrm{s}^{-1}$.

\section{CONCLUSIONS}

A new, accurate experimental method for gaining information to characterize the sliding of polymer materials across surfaces has been presented in this paper. The range of shear and normal forces which are measured by the LFA are intermediate to those measured by conventional tribological testing apparatus and an atomic force microscope. The LFA can probe forces sufficiently large for probes of controlled geometry, which have flat surfaces, to be used; i.e., mesas of known surface area and well-defined roughness and chemical functionality. The mesas are fabricated by silicon micromachining techniques. The controlled surface geometry of the mesas allows average shear and normal stresses to be determined from the measurements: stress information is more valuable for the evaluation of theory than force information. By contrast, both a conventional pin-on-plate tribological tester and an AFM use styli of which the end is not flat but rounded with imprecisely defined geometry, such that stress values cannot readily be extracted from the force measurements. The LFA is sufficiently sensitive to low shear and normal forces such that the mesa can be made with a small enough area so as to ensure full and uniform contact with the opposed polymer surface.

Improved understanding of the process of sliding an elastomer across a surface is expected to shed light on the related process of slip of a polymer melt across a surface. Furthermore, elucidating the mechanism governing friction between an elastomer and a hard surface is an important goal in its own right with implications for key technological applications; e.g., drive devices employing rubber wheels or belts.

Essential differences in the sliding behavior of an elastomer surface across $\mathrm{SiO}$ coated mesas versus across PDMS-OH grafted mesas were observed in the present experiment. Sliding of the elastomer surface across the $\mathrm{SiO}$ mesa at a given velocity and imposed normal force required greater shear stress than sliding across the PDMS-OH mesa. The shear stress for sliding across the PDMS-OH grafted mesa was dependent on the sliding velocity; e.g., near zero imposed normal stress, the shear stress for sliding at a velocity of $38 \mu \mathrm{m} \mathrm{s}^{-1}$ was a factor of four times greater than for sliding at a velocity of $1 \mu \mathrm{m} \mathrm{s}{ }^{-1}$. In contrast, such sensitive dependence of shear stress on sliding velocity was not noted 
for sliding across the $\mathrm{SiO}$ mesas; in fact, a dependence of shear stress on sliding velocity for the $\mathrm{SiO}$ mesas could not be positively identified from the data.

Given the noted differences in sliding behavior of the PDMS elastomer across $\mathrm{SiO}$ coated versus PDMS-OH grafted surfaces, it is worthwhile to consider which aspects of the chemistry and morphology of the mesa surfaces may have been responsible for these differences. As discussed earlier, PDMS is capable of hydrogen bonding to silanol groups on a SiO mesa [Deruelle et al. (1995); Cohen-Addad (1989)]. Given that a finite time is required to form the hydrogen bonds, at a sufficiently high sliding velocity, a decrease in the surface density of hydrogen bonds, with an associated plateau in the increase of shear stress with sliding velocity, is expected. However, in the present experiment, no definitive dependence of shear stress on sliding velocity across the $\mathrm{SiO}$ mesas was noted. In a future study experiments could be performed with a wider range of sliding velocities in order to identify whether an initial increase in shear stress with sliding velocity followed by a plateau occurs. Such data could be compared with kinetic data on the rate of formation of hydrogen bonds to determine whether hydrogen bonding of the PDMS elastomer to the $\mathrm{SiO}$ groups is an important factor in the resultant shear stress. Additionally, an experiment could be conducted in which the silanol groups were shielded by functionalization with, for example, tetradecyltrichlorosilane [Léger et al. (1997); El Kissi et al. (1994)], and the effect of an elimination of hydrogen bonding on the shear stress associated with sliding noted.

The interaction of the elastomer surface with the PDMS-OH melt grafted mesa surfaces is apparently weaker than the interaction with the $\mathrm{SiO}$ mesa surfaces, given the lower shear stress at a given applied normal force and sliding velocity. This may be a result of shielding of the silanol groups from the elastomer by the PDMS-OH chains. This could be further investigated by controlling the surface density of the PDMS-OH by grafting from solutions of varying concentration [Deruelle et al. (1995)]. The technique used in the present investigation, in conjunction with surface treatment techniques applied in studies of polymer slip in recent years, offers a complementary approach to existing techniques to obtain data critical for verification of theories describing polymer/ polymer and polymer/hard surface interactions, especially in the context of slip [de Gennes (1997)].

\section{ACKNOWLEDGMENTS}

This material is based upon work supported in part by the North Atlantic Treaty Organization under a Grant awarded in 1996. Thanks are due to Barry Smalbrugge and the Microelectronics Laboratory at the Eindhoven University of Technology for help with the spin coating and mesa preparation procedures and Lina Sarro of DIMES of the Delft University of Technology for design and manufacture of the probe tips.

\section{References}

Baljon, A. R. C. and M. O. Robbins, "Adhesion and friction of thin films," MRS Bull. 22, 22-26 (1997).

Brochard-Wyart, F., C. Gay, and P.-G. de Gennes, "Slippage of polymer melts on grafted surfaces," Macromolecules 29, 377-382 (1996).

Cohen-Addad, J. P., "Silica-siloxane mixtures. Structure of the adsorbed layer: Chain length dependence," Polymer 30, 1820-1823 (1989).

Cohen-Addad, J. P., C. Roby, and M. Sauviat, "Characterization of chain binding to filler in silicone-silica systems," Polymer 26, 1231-1233 (1985).

de Gennes, P.-G., Soft Interfaces: The 1994 Dirac Memorial Lecture (Cambridge University Press, Cambridge, 1997). 
Deruelle, M., L. Léger, and M. Tirrell, "Adhesion at the solid-elastomer interface: Influence of the interfacial chains," Macromolecules 28, 7419-7428 (1995).

El Kissi, N., L. Léger, J.-M. Piau, and A. Mezghani, "Effect of surface properties on polymer melt slip and extrusion defects," J. Non-Newtonian Fluid Mech. 52, 249-261 (1994).

Georges, J.-M., A. Tonck, J. L. Loubet, D. Mazuyer, E. Georges, and F. Sidoroff, "Rheology and friction of compressed polymer layers adsorbed on solid surfaces," J. Phys. II France 6, 57-76 (1996).

Ghanta, V. G., B. L. Riise, and M. M. Denn, "Disappearance of extrusion instabilities in brass capillary dies," J. Rheol. 43, 435-442 (1999).

Grosch, K. A., "The relation between the friction and visco-elastic properties of rubber," Proc. R. Soc. London, Ser. A 274, 21-39 (1962).

Halley, P. J. and M. E. Mackay, "The effect of metals on the processing of LLDPE through a slit die,' J. Rheol. 38, 41-51 (1994).

Halling, J., "Mechanics of rolling motion," in Principles of Tribology, edited by J. Halling (Macmillan, London, 1975), pp. 174-201.

Hendriks, K. C. P., "'Quantitative measurement of friction dynamics at mesoscopic scales: Development and performance of the LFA," Ph.D. thesis, Eindhoven University of Technology, 2000.

Kurata, M. and Y. Tsunashima, "Viscosity-molecular weight relationships and unperturbed dimensions of linear chain molecules," in Polymer Handbook, edited by J. Brandrup and E. H. Immergut (Wiley, New York, 1989).

Léger, L., H. Hervet, G. Massey, and E. Durliat, "Wall slip in polymer melts,” J. Phys.: Condens. Matter 9, 7719-7740 (1997).

Ludema, K. C. and D. Tabor, "The friction and visco-elastic properties of polymer solids," Wear 9, 329-348 (1966).

Ramamurthy, A. V., "Wall slip in viscous fluids and influence of materials of construction," J. Rheol. 30, 337-357 (1986).

Rhône-Poulenc, "Rhodorsil Oils 47: Technical Data Sheet," 1994.

Suh, N. P., Tribophysics (Prentice-Hall, Englewood Cliffs, NJ, 1986). 